\title{
Recognition of water-induced effects toward enhanced interaction between catalyst and reactant in alcohol oxidation
}

Qianbing Wei, Chang Yu*, Xuedan Song, Yiping Zhong, Lin Ni, Yongwen Ren, Wei Guo, Jinhe Yu and Jieshan Qiu*广

State Key Lab of Fine Chemicals, School of Chemical Engineering, Liaoning Key Lab for Energy Materials and Chemical Engineering, Dalian University of Technology, Dalian, China

*E-mail: chang.yu@dlut.edu.cn, jqiu@dlut.edu.cn 


\section{Reagents and materials}

Benzyl alcohol $\left(\mathrm{C}_{7} \mathrm{H}_{8} \mathrm{O}, \geq 99.0 \%\right.$, CAS\# 100-51-6), benzaldehyde $\left(\mathrm{C}_{7} \mathrm{H}_{6} \mathrm{O}, \geq 99.0 \%\right.$, CAS\# 100-527), 4-methoxybenzyl alcohol $\left(\mathrm{C}_{8} \mathrm{H}_{10} \mathrm{O}_{4}, \geq 98.0 \%\right.$, CAS\# 105-13-5), 4-methylbenzyl alcohol $\left(\mathrm{C}_{8} \mathrm{H}_{10} \mathrm{O}, \geq\right.$ 99.0\%, CAS\# 589-18-4), 4-bromobenzyl alcohol $\left(\mathrm{C}_{7} \mathrm{H}_{7} \mathrm{BrO}, \geq 99.0 \%\right.$, CAS\# 873-75-6), 2-phenethyl alcohol $\left(\mathrm{C}_{8} \mathrm{H}_{10} \mathrm{O}, \geq 98.0 \%\right.$, CAS\# 60-12-8), 3-phenylpropanol $\left(\mathrm{C}_{9} \mathrm{H}_{12} \mathrm{O}, \geq 99.0 \%\right.$, CAS\# 122-97-4), urea $\left(\left(\mathrm{NH}_{2}\right)_{2} \mathrm{CO}, \geq 99.5 \%\right.$, CAS\# 57-13-6), zirconium dioxide $\left(\mathrm{ZrO}_{2}, \geq 99.0 \%\right.$, CAS\# 1314-23-4), silicon dioxide $\left(\mathrm{SiO}_{2}, \geq 98 \%\right.$, CAS\# 14808-60-7), nanometer zinc oxide (nZnO, $\geq 98 \%$, CAS\# 1314-132), nanometer silicon carbide ( $\mathrm{nSiC} \geq 99.5 \%$, CAS\# 409-21-2), and activated carbon (AC, $\geq 98 \%, 7440$ 44-0) were purchased from Sigma-Aldrich. The CNT was purchased from Shenzhen Nanotech Port Co., Ltd. (Shenzhen, China). All chemicals are not further purified and used directly.

\section{Experimental section}

Synthesis of Pd/MgAl-LDO. The MgAl-LDH was fabricated by using a urea-assisted hydrothermal reaction according to our previous reports. ${ }^{1}$ In detail, $\mathrm{Mg}\left(\mathrm{NO}_{3}\right)_{2} \cdot 6 \mathrm{H}_{2} \mathrm{O}(12 \mathrm{mmol}), \mathrm{Al}\left(\mathrm{NO}_{3}\right)_{3} \cdot 9 \mathrm{H}_{2} \mathrm{O}(6$ $\mathrm{mmol})$ and urea $(30 \mathrm{mmol})$ were thoroughly dissolved in $60 \mathrm{~mL}$ of deionized water for $30 \mathrm{~min}$. Then, the obtained solution was added in $100 \mathrm{~mL}$ of autoclave by hydrothermal treatment at $140{ }^{\circ} \mathrm{C}$ for $24 \mathrm{~h}$. The resulting white suspension was then washed in water until neutral and dried at $80{ }^{\circ} \mathrm{C}$. The sample was collected and named as MgAl-LDH. The MgAl-LDH was heated at $800{ }^{\circ} \mathrm{C}$ for $2 \mathrm{~h}$ with a heating rate of $2{ }^{\circ} \mathrm{C} \mathrm{min}{ }^{-1}$ in a $30 \mathrm{~mL} \mathrm{~min}^{-1}$ of flowing $\mathrm{N}_{2}$, yielding MgAl-LDO. The MgAl-LDO was used as a support for configuring Pd catalyst. Incipient wetness impregnation was carried out at room temperature in the presence of the toluene solution of palladium acetate (46-48 wt $\% \mathrm{Pd}$; Aladdin). The impregnated supports were subsequently dried at $60^{\circ} \mathrm{C}$, then reduced in $\mathrm{H}_{2}$ at $150{ }^{\circ} \mathrm{C}$ for $2 \mathrm{~h}$, finally yielding the $\mathrm{Pd} / \mathrm{MgAl}-\mathrm{LDO}$ catalyst. The other Pd catalysts were also prepared following the same method.

\section{Characterization}

The structure of precursor and catalysts was examined by FE-SEM (HITACHI UHR FE-SEM SU8220). TEM and HR-TEM were carried out on a FEI Tecnai G2 F30. The Dimension ICON atomic force microscope (AFM) was used to detect the thickness of the material in ScanAsyst model. The XRD patterns were collected using a Rigaku D/Max 2400 diffractometer at room temperature with a scan range from $5^{\circ}$ to $85^{\circ}$ using a wide angle X-ray diffraction (D/Max-2400, Rigaku, Japan) equipped with $\mathrm{Cu}-\mathrm{Ka}$ radiation $(1.5406 \AA$ ). The pore structure of MgAl-LDO was determined by Micromeritics 3Flex 3500 system, where BET equation was used to calculate the surface areas and pore volume. Before measurements, the samples were outgassed at $250^{\circ} \mathrm{C}$ for $15 \mathrm{~h}$ until the residual pressure is less than $10^{-4}$ Pa. ICP-OES was carried out on PerkinElmer Optima 2000DV. XPS test was carried out on Thermo ESCALAB 250 using a single Al-K-X-ray source operating at $300 \mathrm{~W}$ and $15 \mathrm{kV}$ of voltage. The samples were placed in an ultrahigh vacuum chamber and the spectra was collected at ambient temperature. $9 \mathrm{mg}$ of $\mathrm{Pd} / \mathrm{MgAl}-\mathrm{LDO}$ was added to the mixed solution made of $2 \mathrm{~mL}$ toluene and $2 \mathrm{~mL}$ deionized water, then treated by ultrasound for $1 \mathrm{~min}$, standing $1 \mathrm{~h}$, forming Pickering emulsion. For identification of emulsion type, the red rhodamine B dissolved in water was injected in the emulsion on the glass slide. If the emulsion and red droplet are combined, the oil-in-water type is formed. If not, the water-in-oil type is formed. Then the state of emulsion droplet was monitored by ZEISS Scope.A1 instrument. The contact angles of water or toluene on quartz plate were measured using a KINO SL150E instrument with high speed camera. Before testing, the sample should be pressed in a disk. TGA experiments were performed in the NETZSCH STA 449 F3 Thermal analyzer. For each experiment, $5.00 \mathrm{mg}$ of sample, placed in a standard environment at $50 \%$ humidity for 2 days, was 
placed in alumina crucible and the TGA curve was recorded according to the test procedure shown in the Figure S7.

Attenuated total reflection infrared spectroscopy (ATR-IR) and diffuse reflectance infrared Fourier transform spectra (DRIFTS) were recorded on a Bruker INVENIO R spectrometer installed with a highly sensitive MCT detector and a diffuse IR heating chamber. The Pd/MgAl-LDO was first purged in $\mathrm{Ar}$ in at $120{ }^{\circ} \mathrm{C}$ for $1 \mathrm{~h}$. After cooling the sample to $30{ }^{\circ} \mathrm{C}$ under a continuous flowing Ar, a background spectrum was collected. Subsequently, the water was introduced by bubbling with $30 \mathrm{~mL}$ $\min ^{-1}$ of Ar for $30 \mathrm{~min}$ or not and the sample was exposed to the mixed gas of $10 \mathrm{vol} \% \mathrm{CO} / \mathrm{Ar}$ with a rate of $20 \mathrm{~mL} \mathrm{~min}^{-1}$ for 30 min until saturation. Next, the sample was purged in Ar with a rate of $20 \mathrm{~mL}$ $\mathrm{min}^{-1}$ for $30 \mathrm{~min}$ to remove the CO. Finally, the DRIFTS was collected with 64 scans.

The $\mathrm{CO}$ chemisorption (CO Pulse), $\mathrm{H}_{2} \mathrm{O}$ Pulse, temperature programmed desorption (TPD) and hydrogen temperature programmed reduction $\left(\mathrm{H}_{2}\right.$-TPR) were examined in a Micromeritics AutoChem II 2920 apparatus. In particular, for each experiment, $30 \mathrm{mg}$ of sample was placed in a U-shaped quartz reactor supported over a quartz wool bed. The catalyst was firstly pretreated at $200{ }^{\circ} \mathrm{C}$ for CO Pulse or $500{ }^{\circ} \mathrm{C}$ for $\mathrm{H}_{2} \mathrm{O}$ Pulse and TPD in a He atmosphere with a flow rate of $30 \mathrm{~mL} \mathrm{~min}{ }^{-1}$. For Pulse experiment, $\mathrm{H}_{2} \mathrm{O}$ vapor or $\mathrm{CO}$ was then pulsed until adsorption saturation after the pretreated samples were cooled to $35^{\circ} \mathrm{C}$ for $\mathrm{CO}$ Pulse) or $60{ }^{\circ} \mathrm{C}$ for $\mathrm{H}_{2} \mathrm{O}$ Pulse, simultaneously collecting signal. For TPD experiment, the catalyst was saturated with $\mathrm{CO}_{2}$ or $\mathrm{O}_{2}$ at $60{ }^{\circ} \mathrm{C}$. After saturation, the reactor was purged in $30 \mathrm{~mL} \mathrm{~min}{ }^{-1} \mathrm{He}$ flow for $60 \mathrm{~min}$. The TPD experiment was then carried out from 60 to $800{ }^{\circ} \mathrm{C}$ with a heating rate of $10{ }^{\circ} \mathrm{C} \mathrm{min}-1$, simultaneously collecting signal. For $\mathrm{H}_{2} \mathrm{O}$ Pulse coupled with TPD, the sample and reactor was purged with $30 \mathrm{~mL} \mathrm{~min}^{-1} \mathrm{He}$ flow for $60 \mathrm{~min}$ after $\mathrm{H}_{2} \mathrm{O}$ Pulse. Then heating desorption was carried out, simultaneously collecting signal. For $\mathrm{H}_{2}$-TPR experiment without water, the catalyst was firstly pretreated at $120{ }^{\circ} \mathrm{C}$ in a flowing Ar with $30 \mathrm{~mL} \mathrm{~min}^{-1}$ for $60 \mathrm{~min}$ and cooled to 60 ${ }^{\circ} \mathrm{C}$. Then, the TPR experiments were carried out to heat the catalysts to $500{ }^{\circ} \mathrm{C}$ at a rate of $10{ }^{\circ} \mathrm{C} \mathrm{min}{ }^{-1}$ in a flowing mixed gas of $10 \mathrm{vol} \% \mathrm{H}_{2} / \mathrm{Ar}$. For Pd/MgAl-LDO sample with pre-adsorbed water, $\mathrm{H}_{2} \mathrm{O}$ vapor was pulsed until adsorption saturation after the sample was cooled to $60{ }^{\circ} \mathrm{C}$. Then the TPR experiment was also carried out following the above procedure.

The Raman experiments were examined using the $532 \mathrm{~nm}$ Raman laser in a LabRAM HR Evolution Raman spectrometer with a CCD detector, and the corresponding spectra were recorded. For liquid BA or BAD, it can be enclosed in a capillary quartz tube for direct testing. For clean catalyst, it was placed in a quartz plate and gently flattened for direct testing. For quasi-in situ Raman experiments, 2-3 mg of catalyst was first dispersed into toluene $(2 \mathrm{~mL})$. The as-made solution was dropped onto the surface of the quartz plate and dried on a hot plate to form a catalyst coating for test. Then it was placed in a quartz tube and heated at $120{ }^{\circ} \mathrm{C}$ for $2 \mathrm{~h}$ in a $30 \mathrm{~mL} \mathrm{~min}^{-1}$ of $\mathrm{N}_{2}$ to remove the loosely bound water on the surface of catalyst, as shown in Figure S14. Subsequently, the quartz tube was cooled to room temperature naturally. By controlling the valve (\# 1-5), the liquid BA or BAD was introduced by $\mathrm{N}_{2}$ bubbling $\left(30 \mathrm{~mL} \mathrm{~min}^{-1}\right)$ for $30 \mathrm{~min}$. The quartz tube was finally purged in a flowing $\mathrm{N}_{2}$ for $30 \mathrm{~min}$. And, the Raman spectrum was recorded. For adsorption of BA over Pd/MgAl-LDO with water, the water was introduced by $\mathrm{N}_{2}$ bubbling with $30 \mathrm{~mL} \mathrm{~min}^{-1}$ for $30 \mathrm{~min}$ before adsorption of BA or BAD.

\section{Typical procedure for the oxidation of BA.}

Selective oxidation of BA was carried out in a $40 \mathrm{~mL}$ of glass reactor (with height: diameter $=2: 1$ ) with reflux condensation at atmospheric pressure by oxygen bubbling. For a typical run, 2 mmol of BA, $45 \mathrm{mg}$ of catalysts and $20 \mathrm{~mL}$ of solvent volume were added into the reactor, accompanied by ultrasound treatment for $1 \mathrm{~min}$ to form the Pickering emulsion. Then the reactor was heated at $85{ }^{\circ} \mathrm{C}$ 
with $10 \mathrm{~mL} \mathrm{~min}^{-1}$ of $\mathrm{O}_{2}$ flowing. After the different reaction periods, the reaction solution was filtered through a membrane $(0.22 \mu \mathrm{m})$ and the products were analyzed by Gas chromatography with flame ionization detector (FID) using a capillary column (SE-54, $30 \mathrm{~m} \times 0.32 \mathrm{~mm} \times 0.6 \mu \mathrm{m})$.

\section{Calculations.}

All the calculations were carried out using density functional theory (DFT) with the Vienna Ab-inito Simulation Package (VASP) ${ }^{2}$ under Generalized-Gradient Approximate (GGA) with PBE exchangecorrelation functional. ${ }^{3}$ The cutoff energy was set to $500 \mathrm{eV}$, and the Monkhorst-Pack mesh with $5 \times 5 \times 1$ $\mathrm{k}$ points was applied for the Brillouin zone integration. The energy convergence criteria for electronic and ionic iterations were $10^{-4} \mathrm{eV}$ and $-0.05 \mathrm{eV} \AA^{-1}$, respectively. The adsorption energy $(E)$ was defined as follows: $E=E_{\mathrm{a}-\mathrm{s}}-E_{\mathrm{a}}-E_{\mathrm{s}}$, where $E_{\mathrm{a}-\mathrm{s}}, E_{\mathrm{a}}$, and $E_{\mathrm{s}}$ corresponded to the energy of adsorbate together with slab, the energy of absorbate and the energy of slab, respectively. 


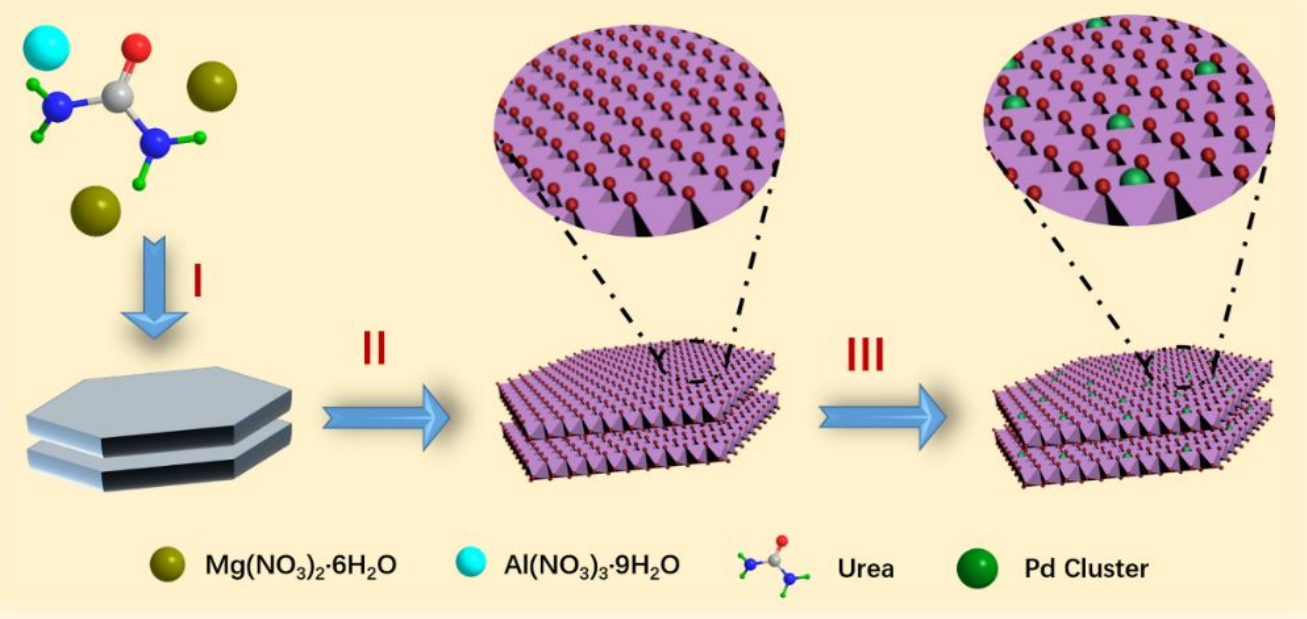

Scheme 1. Diagram of the synthesis process for Pd/MgAl-LDO, I : Hydrothermal method. II: Calcination. III: Wet impregnation and heating reduction. Therein, 2D MgAl-layered double hydroxide Nanosheets (MgAl-LDH) precursor was prepared following the previous literature. 

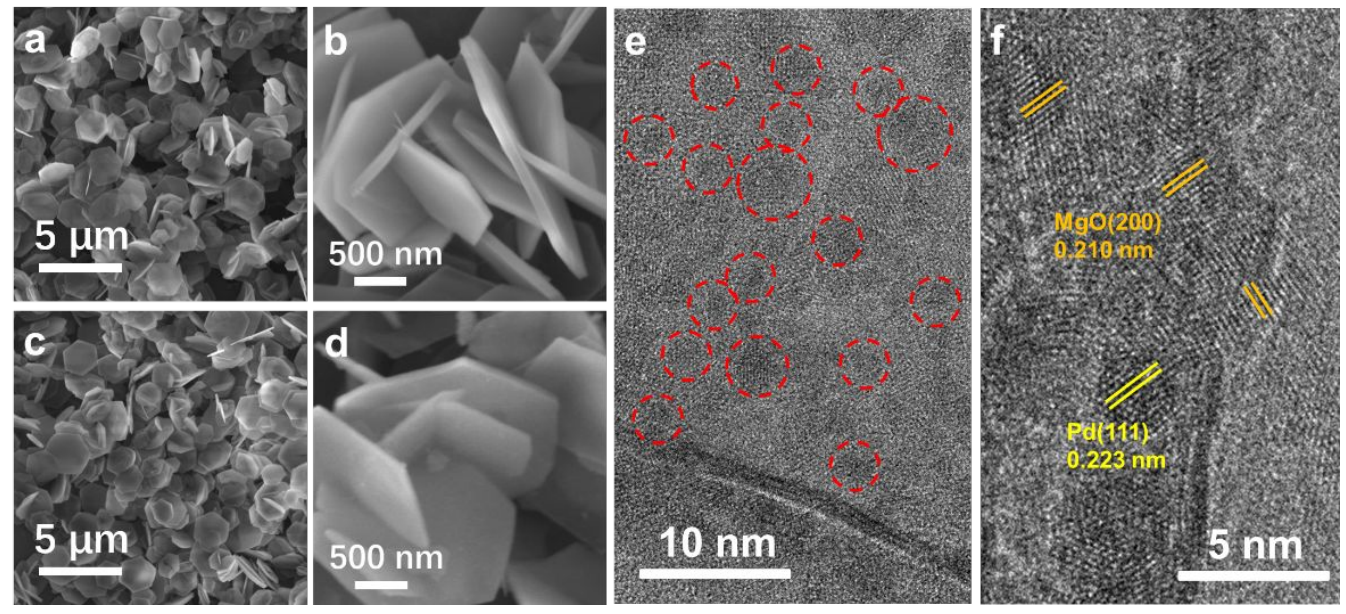

Figure S1. (a-b) SEM images of bulk MgAl-LDH. (c-d) SEM images of bulk MgAl-LDO. (e, f) HRTEM images of Pd/MgAl-LDO. 

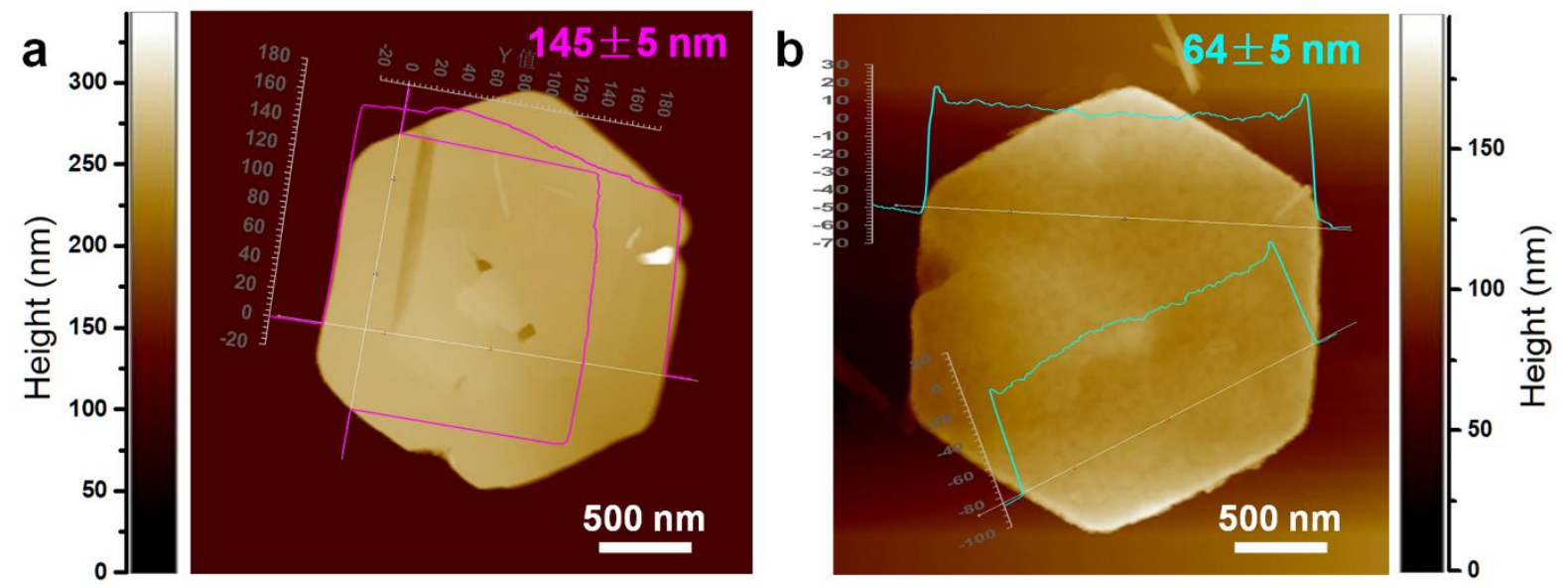

Figure S2. AFM image and height profiles of (a) MgAl-LDH precursor and (b) MgAl-LDO on mica substrate. 


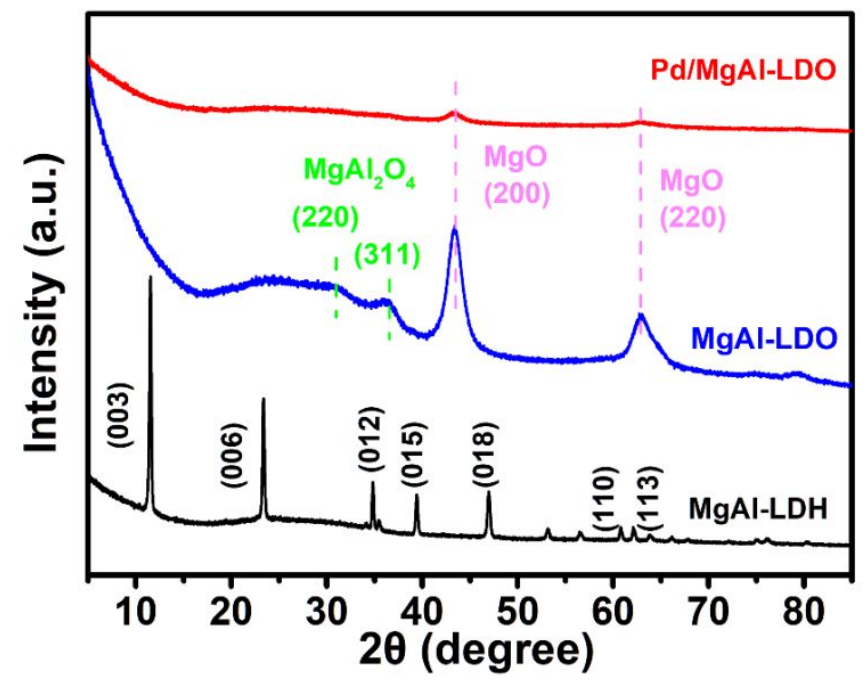

Figure S3. XRD patterns of MgAl-LDH precursor, MgAl-LDO and Pd/MgAl-LDO catalyst. The assynthesized MgAl-LDH flakes were well crystallized. After calcination at $800{ }^{\circ} \mathrm{C}$ for $2 \mathrm{~h}$, the hydrotalcite-like structure of MgAl-LDH was completely destroyed, leaving $\mathrm{MgO}$ and $\mathrm{MgAl}_{2} \mathrm{O}_{4}$ as the main components for the resulting MgAl-LDO. The Pd-related diffraction peaks were not observed on $\mathrm{Pd} / \mathrm{MgAl}-\mathrm{LDO}$, implying the ultrafine distribution of Pd nanoparticles. 


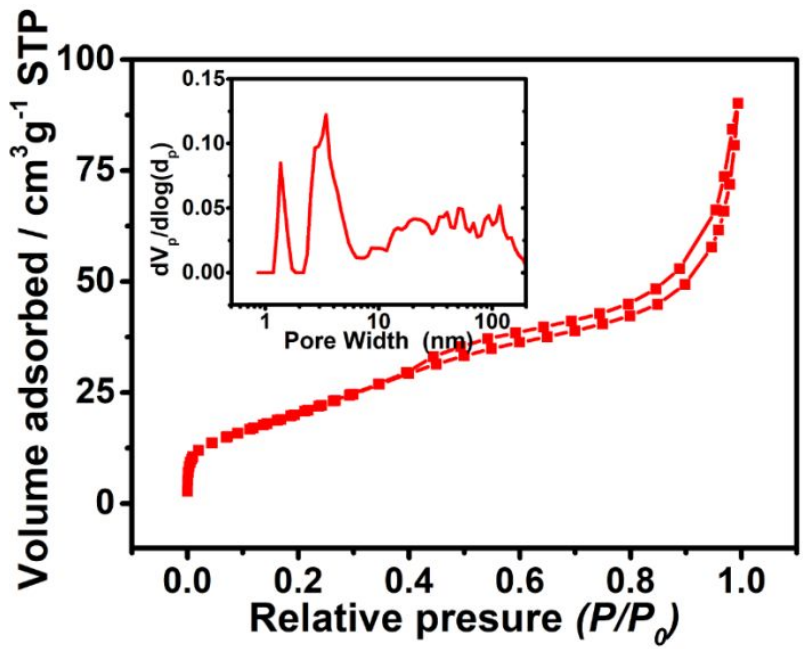

Figure S4. $\mathrm{N}_{2}$ adsorption/desorption isotherms of MgAl-LDO at $77 \mathrm{~K}$ and the corresponding pore size distributions (inset) calculated by the Brunauer-Emmett-Teller (BET) method. The resulting surface area and pore volume are $83 \mathrm{~m}^{2} \mathrm{~g}^{-1}$ and $0.03 \mathrm{~cm}^{3} \mathrm{~g}^{-1}$, respectively. 


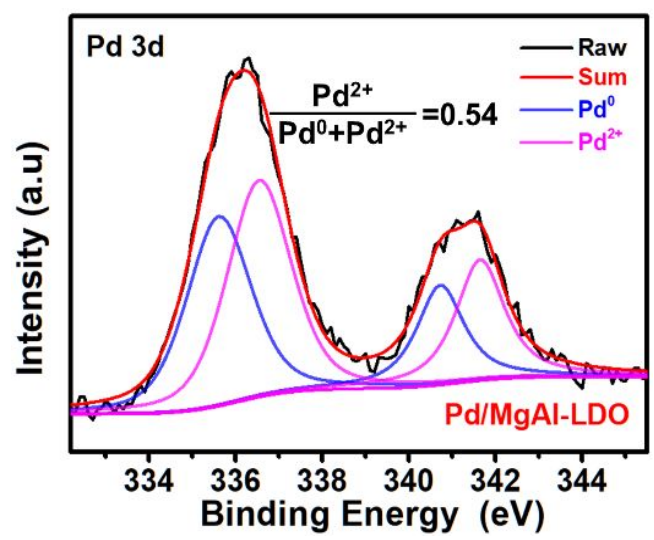

Figure S5. Original and fitted Pd 3d XPS spectra of fresh Pd/MgAl-LDO. 


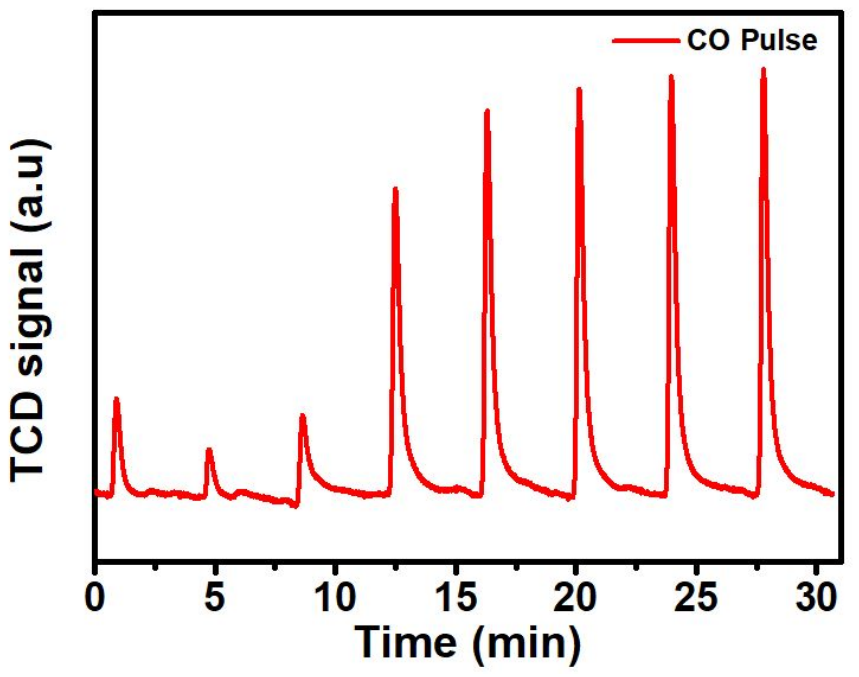

Figure S6. CO Pulse profile of $\mathrm{Pd} / \mathrm{MgAl}-\mathrm{LDO}$. The dispersion of $\mathrm{Pd}$ on the surface of catalyst is $45 \%$. 


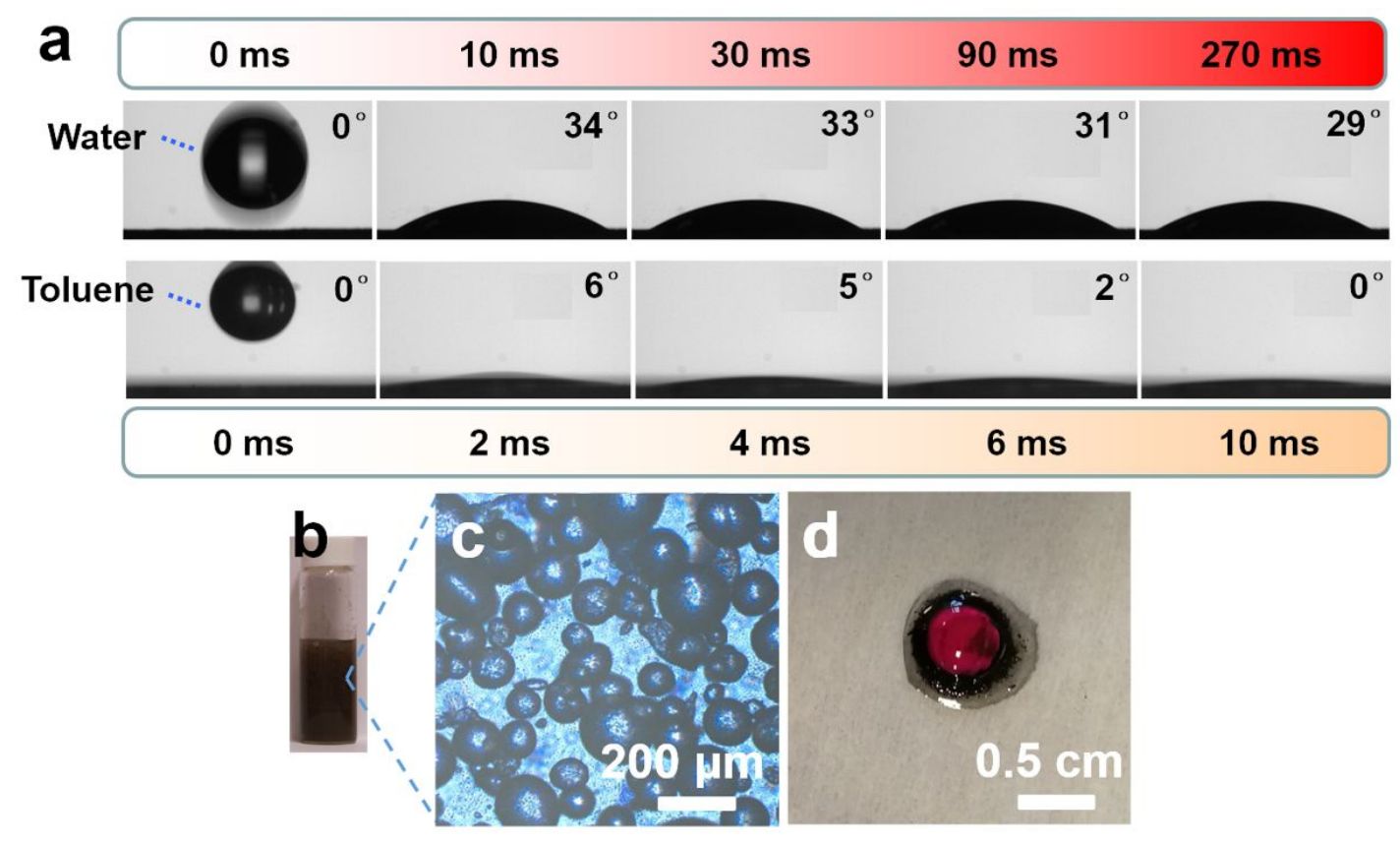

Figure S7. (a) Images of contact angle between Pd/MgAl-LDO disk and a water or toluene droplet; (b) Digital photo and (c) optical microscopy image of the water/toluene emulsion stabilized by Pd/MgAlLDO; (d) Digital photo of emulsion stabilized by $\mathrm{Pd} / \mathrm{MgAl}-\mathrm{LDO}$ in the presence of hydrophilic red rhodamine $\mathrm{B}$, indicative the formation of water-in-oil emulsion. 

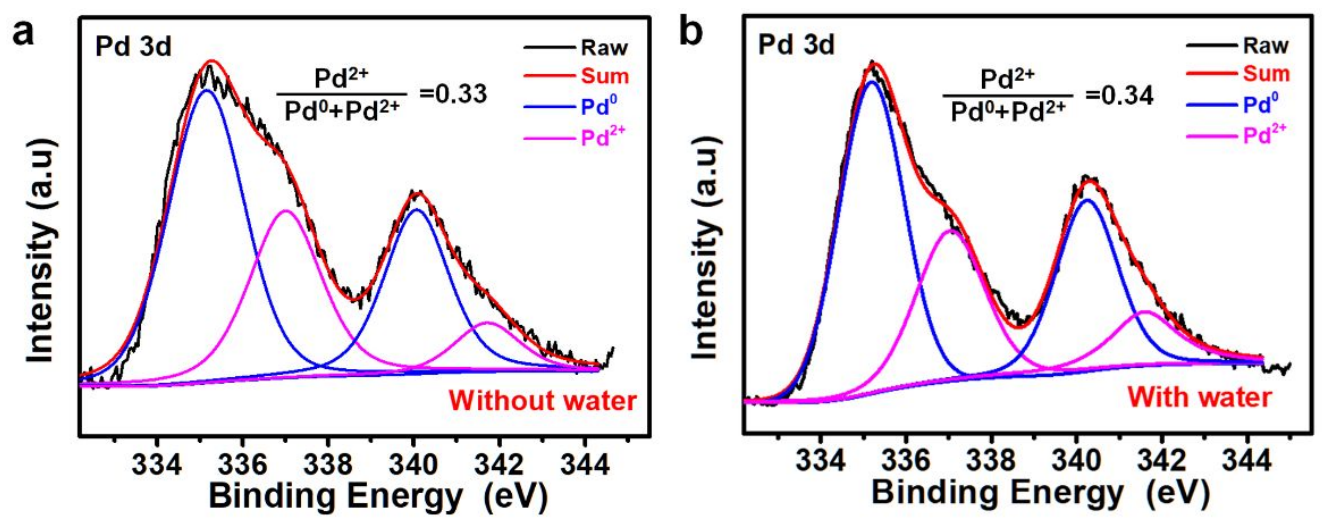

Figure S8. Pd 3d XPS spectra of Pd/MgAl-LDO (a) without water and (b) with water under the gasphase reaction conditions. Pretreatment process of catalyst: The Pd/MgAl-LDO was placed in a quartz tube and heated at $120{ }^{\circ} \mathrm{C}$ for $2 \mathrm{~h}$ in $\mathrm{N}_{2}$ atmosphere with a $30 \mathrm{~mL} \mathrm{~min}^{-1}$ to remove the loosely bound water on the surface of catalyst, as shown in Figure S14 of the revised supporting information. Subsequently, the quartz tube was cooled to room temperature naturally. By controlling the valve (\# 1-5), the liquid BA was introduced by $\mathrm{N}_{2}$ bubbling $\left(30 \mathrm{~mL} \mathrm{~min}{ }^{-1}\right)$ for $30 \mathrm{~min}$. The quartz tube was finally purged with $\mathrm{N}_{2} 30 \mathrm{~mL} \mathrm{~min}^{-1}$ for $30 \mathrm{~min}$. The sample was heated to $85{ }^{\circ} \mathrm{C}$ in a flowing $\mathrm{O}_{2}(30 \mathrm{~mL}$ $\min ^{-1}$ ) for $30 \mathrm{~min}$ and cooled to room temperature naturally. Then XPS experiment was carried out. For adsorption of BA over Pd/MgAl-LDO with water, the water was introduced by $\mathrm{N}_{2}$ bubbling with $30 \mathrm{~mL}$ $\min ^{-1}$ for $30 \mathrm{~min}$ before adsorption of BA. 


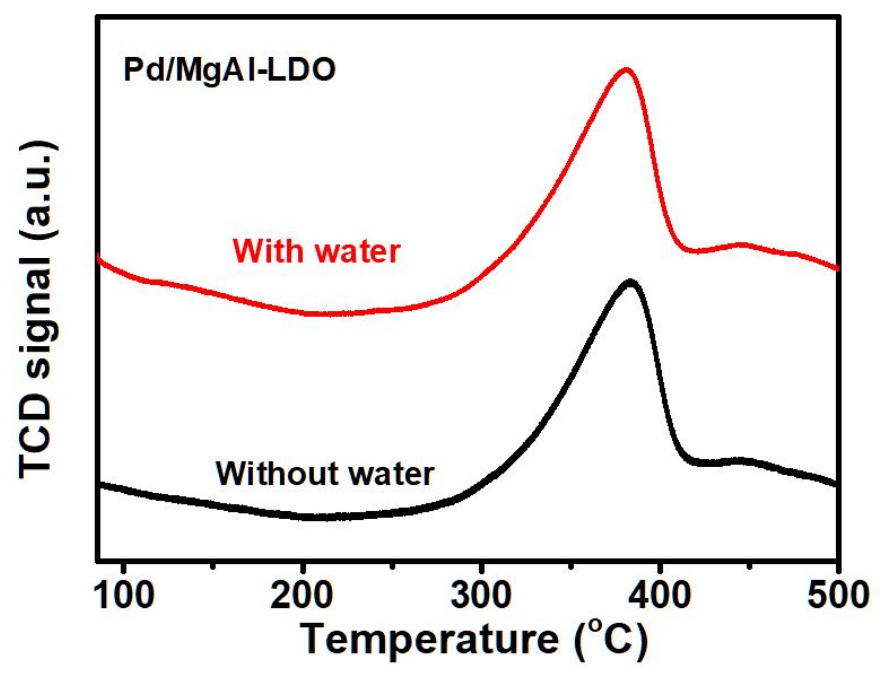

Figure S9. $\mathrm{H}_{2}$-TPR profiles of $\mathrm{Pd} / \mathrm{MgAl}-\mathrm{LDO}$ without or with water. 


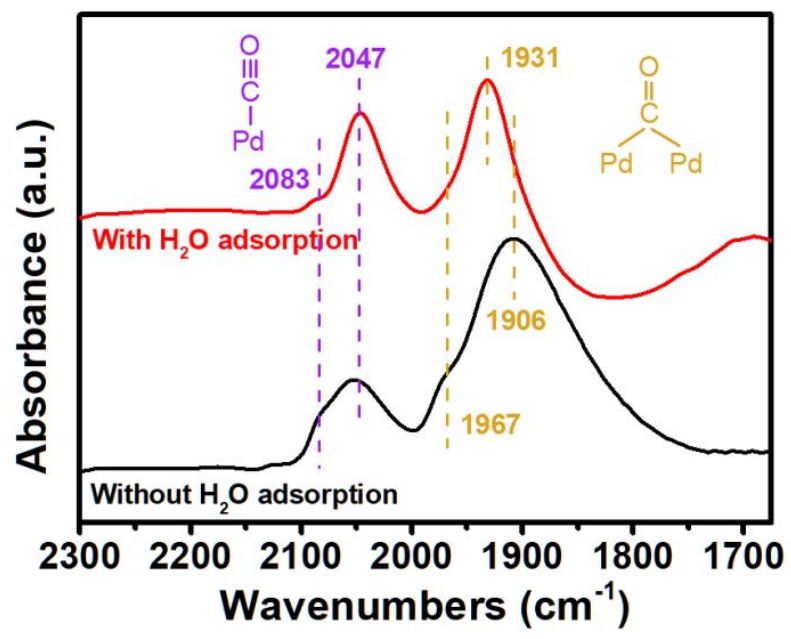

Figure S10. In situ DRIFTS of CO chemisorption over Pd/MgAl-LDO. 


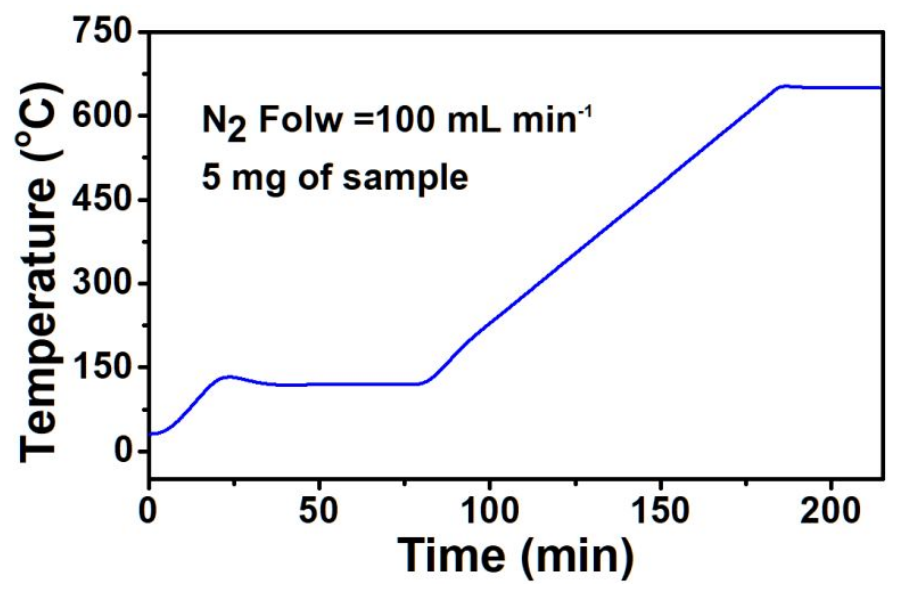

Figure S11. The measurement conditions of TGA. 


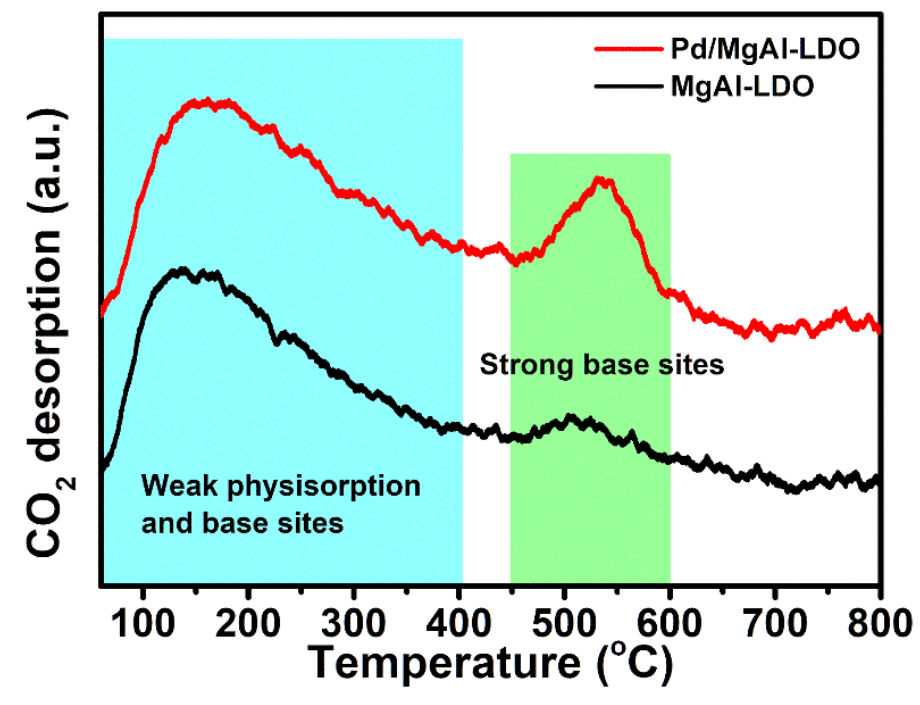

Figure S12. $\mathrm{CO}_{2}$-TPD profiles of MgAl-LDO and Pd/MgAl-LDO. The anchoring of Pd resulted in an increase for strong base site concentration from 0.041 to $0.166 \mathrm{mmol} \mathrm{g}^{-1}$. 


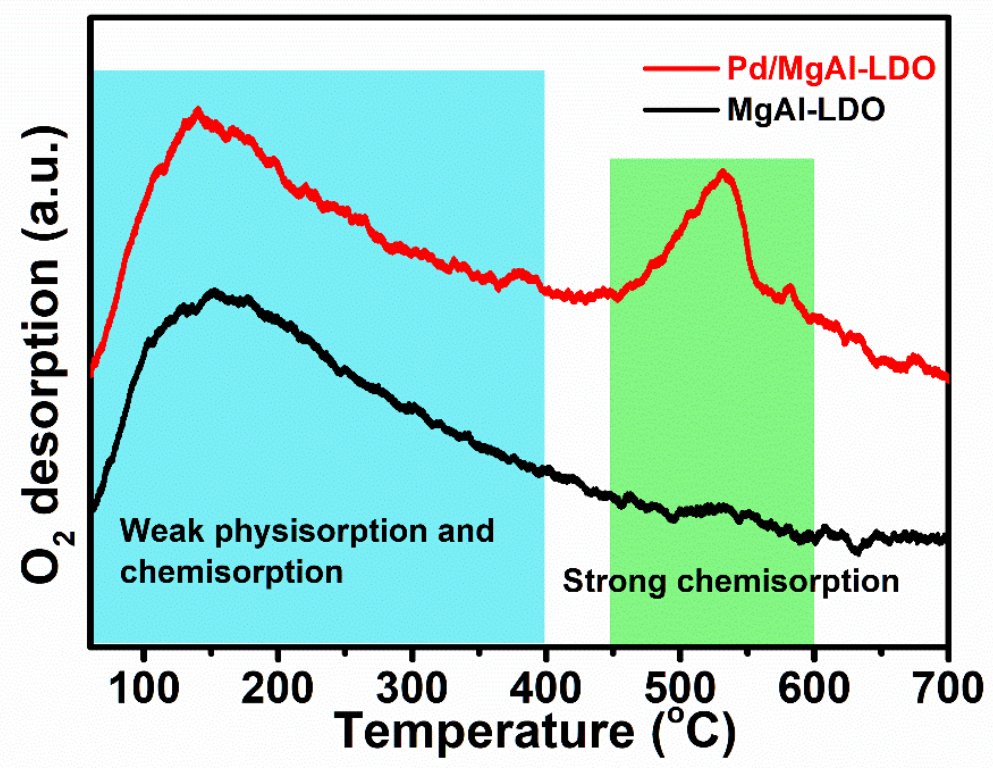

Figure S13. $\mathrm{O}_{2}$-TPD profiles of $\mathrm{MgAl}-\mathrm{LDO}$ and $\mathrm{Pd} / \mathrm{MgAl}-\mathrm{LDO}$. A new oxygen desorption peak appears in the high temperature region due to $\mathrm{Pd}$ anchoring indicating that lattice oxygen is activated at the peripheral sites of $\mathrm{Pd} / \mathrm{MgAl}-\mathrm{LDO}$ interface. 


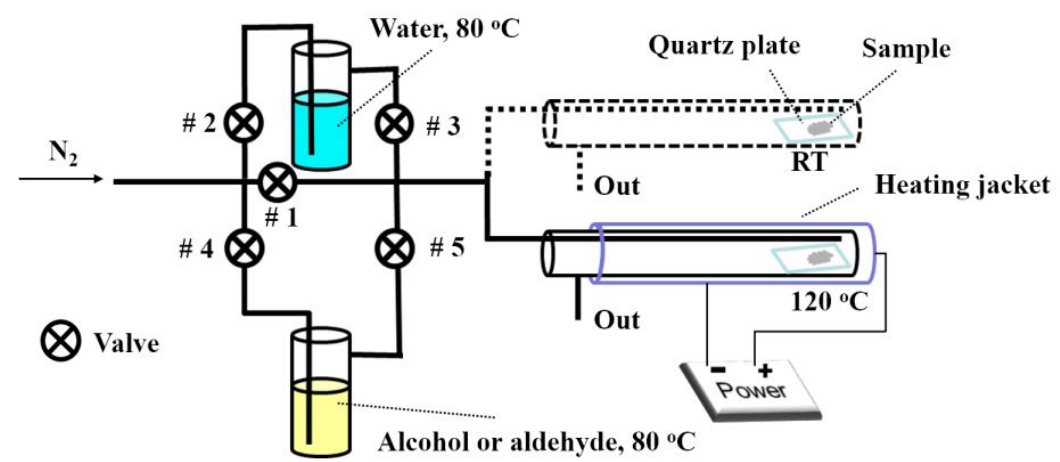

Figure S14. Schematic of sample treatment process for Raman measurement. 


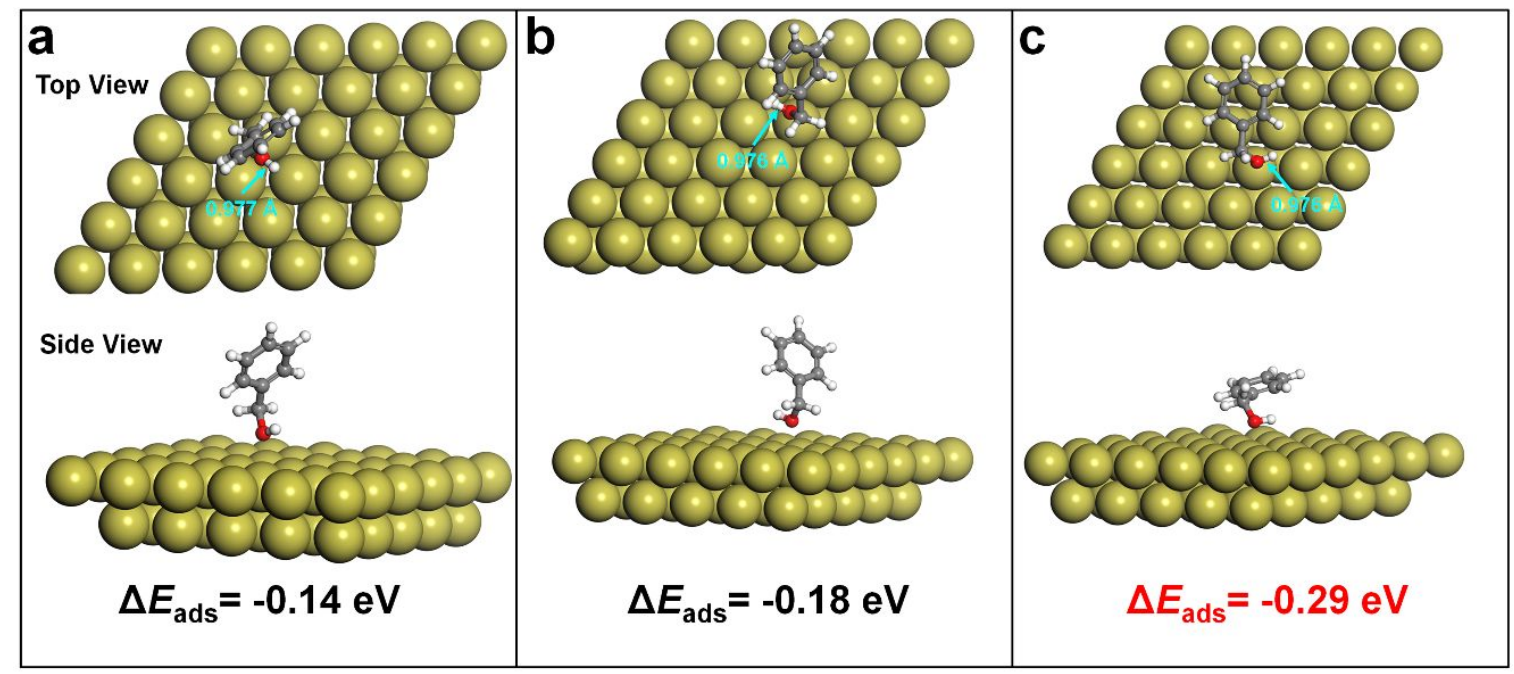

Figure S15. Top and side view of optimized structure for BA adsorbed on Pd (111) and their adsorption energies. (a) Hollow site and (b) top site by vertical adsorption, (c) top site by parallel adsorption. 


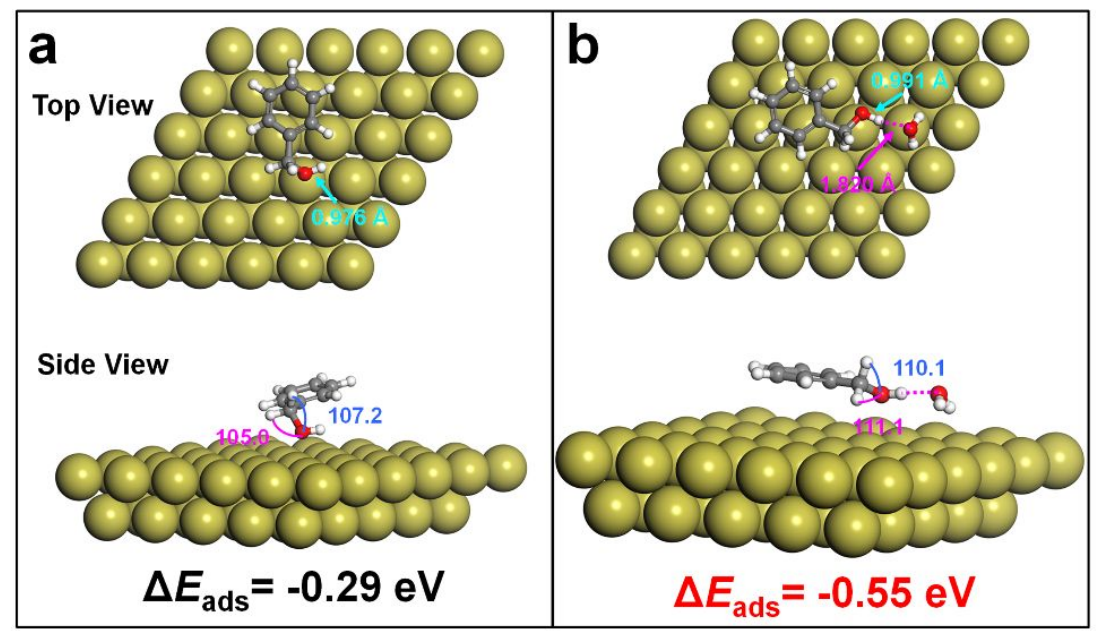

Figure S16. Top and side view of optimized structure for BA parallel adsorbed on top site of Pd (111) and their adsorption energies. (a) Without water, (b) With water. In the presence of water, the adsorption energy $(E)$ of BA was defined as follows: $E_{\mathrm{ads}, \mathrm{BA}}=E_{\mathrm{BA}-\left(\mathrm{Pd}(111)+\mathrm{H}_{2} \mathrm{O}\right)}-E_{\mathrm{BA}}-E_{\mathrm{Pd}(111)+\mathrm{H}_{2} \mathrm{O}}$, where $E_{\mathrm{BA}-\left(\mathrm{Pd}(111)+\mathrm{H}_{2} \mathrm{O}\right)}, E_{\mathrm{BA}}$, and $E_{\mathrm{Pd}(111)+\mathrm{H}_{2} \mathrm{O}}$ corresponded to the energy of adsorbate $(\mathrm{BA})$ together with slab $\left(\mathrm{Pd}(111)+\mathrm{H}_{2} \mathrm{O}\right)$, the energy of absorbate and the energy of slab, respectively. The adsorption energy of BA is composed of the hydrogen bond energy between $\mathrm{BA}$ and $\mathrm{H}_{2} \mathrm{O}$ and the interaction between BA and $\mathrm{Pd}(111)$. The hydrogen bond energy is calculated $\left(\Delta E=E_{\mathrm{BA}+\mathrm{H}_{2} \mathrm{O}}-E_{\mathrm{BA}}-E_{\mathrm{H}_{2} \mathrm{O}}\right)$ and the corresponding hydrogen bond energy is $-0.22 \mathrm{eV}$. This also proves that the water molecule can indeed enhance the adsorption of BA on Pd(111) surface. 


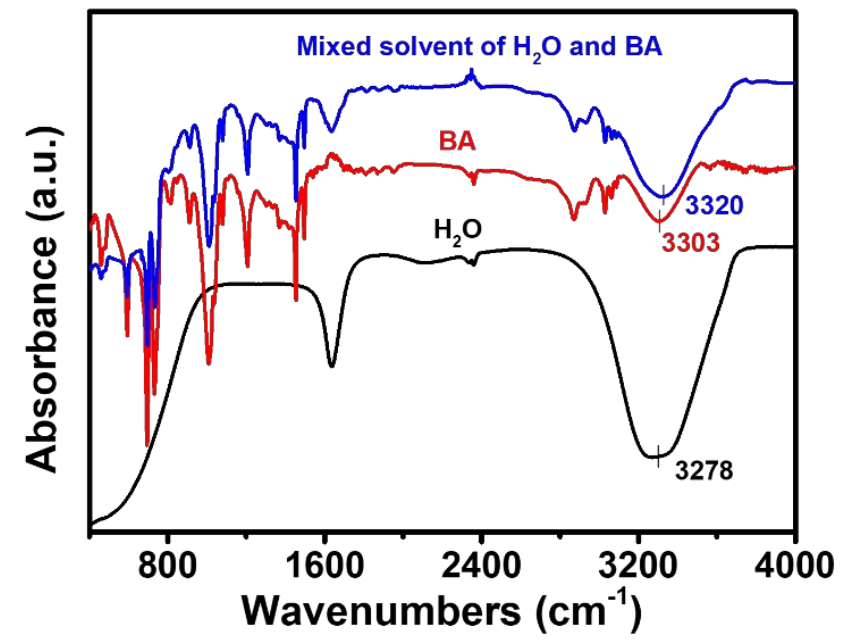

Figure S17. ATR-IR spectra recorded for water, BA and mixed solvent of $\mathrm{H}_{2} \mathrm{O}$ and BA. 

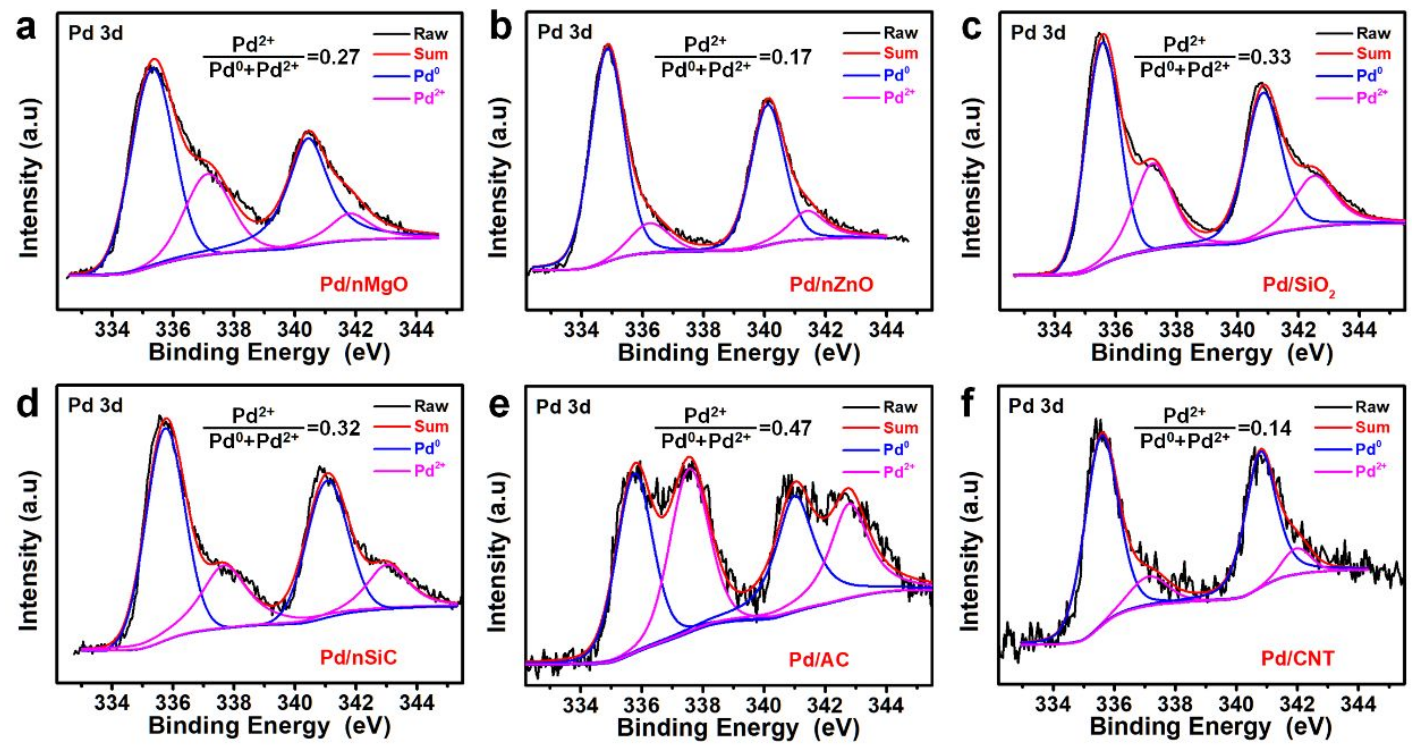

Figure S18. Pd 3d XPS spectra of (a) $\mathrm{Pd} / \mathrm{nMgO}$, (b) $\mathrm{Pd} / \mathrm{nZnO}$, (c) $\mathrm{Pd} / \mathrm{SiO}_{2}$, (d) $\mathrm{Pd} / \mathrm{SiC}$, (e) $\mathrm{Pd} / \mathrm{AC}$ and (f) $\mathrm{Pd} / \mathrm{CNT}$. 


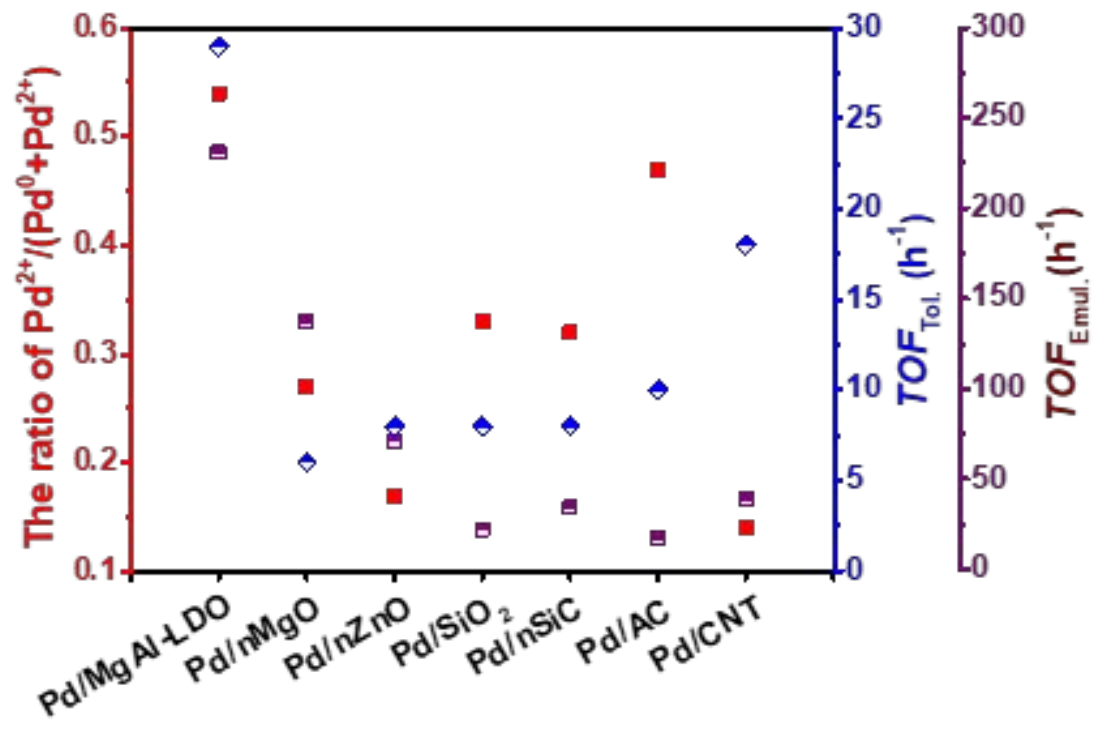

Figure S19. The relationship between the ratio of $\mathrm{Pd}^{2+}$ and the activity of catalysts in toluene system and emulsion system over various supports. 
Table S1: Effect of the amount of water on the catalytic activity of Pd/MgAl-LDO for oxidation of BA.

\begin{tabular}{llcccc}
\hline Entry & Catalyst & $\begin{array}{c}\text { Water in solvent } \\
{\left[\mathbf{V}_{\mathbf{w}} /\left(\mathbf{V}_{\mathbf{w}}+\mathbf{V}_{\mathbf{t}}\right)\right]}\end{array}$ & $\begin{array}{c}\text { Conv. } \\
{[\mathbf{\%}]}\end{array}$ & $\begin{array}{c}\text { Sel. } \\
{[\%]}\end{array}$ & TOF $^{\mathbf{a}}\left[\mathbf{h}^{-1}\right]$ \\
\hline 1 & MgAl-LDO & 0.5 & 3.8 & $>99$ & -- \\
2 & Pd/MgAl-LDO & 0 & 20.5 & $>99$ & 128 \\
3 & Pd/MgAl-LDO & 0.01 & 28.3 & $>99$ & 185 \\
4 & Pd/MgAl-LDO & 0.125 & 77.9 & $>99$ & 530 \\
5 & Pd/MgAl-LDO & 0.25 & 95.6 & $>99$ & 677 \\
6 & Pd/MgAl-LDO & 0.5 & 99.5 & $>99$ & 694 \\
7 & Pd/MgAl-LDO & 0.75 & 17.9 & $>99$ & 79 \\
\hline
\end{tabular}

Reaction conditions: BA (2 mmol), catalyst $(45 \mathrm{mg}), 1 \mathrm{~h}, 85^{\circ} \mathrm{C}$, total volume $20 \mathrm{~mL}\left(\mathrm{~V}_{\mathrm{w}}+\mathrm{V}_{\mathrm{t}}\right)$, w: water, $\mathrm{t}$ : toluene (as oil phase), $\mathrm{O}_{2}$ flowing rate of $10 \mathrm{~mL} \mathrm{~min}^{-1}$.

a: $\mathrm{TOF}=(\mathrm{mol}$ number of converted BA molecule $) /($ mol number of active $\mathrm{Pd}$ atoms $) /($ reaction time, $\mathrm{h})$, $0.012 \mathrm{~mol} \% \mathrm{Pd}$ (based on ICP-OES and CO Pulse results). 
Table S2: Comparison of Raman band for BA in different states ${ }^{\mathrm{a}}$.

Raman (295 K)

\begin{tabular}{|c|c|c|c|}
\hline BA & $\begin{array}{l}\text { BA over Pd/MgAl- } \\
\text { LDO without water }\end{array}$ & $\begin{array}{c}\text { BA over } \\
\text { Pd/MgAl-LDo } \\
\text { with water }\end{array}$ & Assignment ${ }^{4}$ \\
\hline $407(w)$ & N/A & $436(w)$ & $\begin{array}{c}\text { Out-of-plane deformation of phenyl } \\
\text { ring }\end{array}$ \\
\hline $620(\mathrm{~m})$ & N/A & $602(w)$ & $\begin{array}{l}\text { In-plane bending vibration of } \\
\text { phenyl ring }\end{array}$ \\
\hline 1002 (vs) & N/A & N/A & C-C stretching of phenyl \\
\hline $1030(\mathrm{~m})$ & N/A & $1056(w)$ & C-O stretching \\
\hline $1160(\mathrm{~m})$ & N/A & N/A & $\mathrm{CH}_{2}$ bending \\
\hline $1179(w)$ & N/A & N/A & Phenyl C-C-H in-plane bending \\
\hline $1208(\mathrm{~m})$ & N/A & $1208(w)$ & $=\mathrm{CH}$ in-plane bending \\
\hline $1461(w)$ & N/A & N/A & $\mathrm{C}=\mathrm{C}$ aromatic stretching \\
\hline $1585(\mathrm{~m})$ & N/A & N/A & $\mathrm{C}=\mathrm{C}$ aromatic stretching \\
\hline $1605(\mathrm{~m})$ & N/A & N/A & $\mathrm{C}=\mathrm{C}$ aromatic stretching \\
\hline $1694(w)$ & N/A & N/A & $\mathrm{C}=\mathrm{C}$ aromatic stretching \\
\hline
\end{tabular}

${ }^{a}$ where all symbols represent the intensity of the Raman band as below.

vs-very strong $\quad$ s-strong m-medium

w-weak N/A-not available 
Table S3: Comparison of Raman band of BAD in different states ${ }^{\text {a }}$.

Raman (295 K)

\begin{tabular}{|c|c|c|c|}
\hline BAD & $\begin{array}{l}\text { BAD over Pd/MgAl- } \\
\text { LDO without water }\end{array}$ & $\begin{array}{c}\text { BAD over } \\
\text { Pd/MgAl-LDo } \\
\text { with water }\end{array}$ & Assignment $^{5}$ \\
\hline $617(\mathrm{~m})$ & N/A & N/A & $\begin{array}{l}\text { Phenyl ring vibration in-plane } \\
\text { bending }\end{array}$ \\
\hline $832(\mathrm{~m})$ & N/A & N/A & $=\mathrm{CH}$ out-of-plane bending \\
\hline 1003 (vs) & N/A & N/A & Phenyl C-C stretching \\
\hline $1025(\mathrm{~m})$ & N/A & N/A & $=\mathrm{CH}$ in-plane bending \\
\hline $1165(\mathrm{~m})$ & N/A & N/A & $=\mathrm{CH}$ in-plane bending \\
\hline $1206(s)$ & $\mathrm{N} / \mathrm{A}$ & N/A & $=\mathrm{CH}$ in-plane bending \\
\hline $1457(w)$ & N/A & N/A & $\mathrm{C}=\mathrm{C}$ aromatic stretching \\
\hline 1599 (s) & N/A & N/A & $\mathrm{C}=\mathrm{C}$ aromatic stretching \\
\hline $1701(\mathrm{~s})$ & N/A & N/A & $\mathrm{C}=\mathrm{O}$ stretching \\
\hline \multicolumn{4}{|c|}{ a where all symbols represent the intensity of the Raman band as below. } \\
\hline vs-very strong & s-strong & m-medium & \\
\hline w-weak & N/A-not available & & \\
\hline
\end{tabular}


Table S4. Comparison of performance of various Pd catalysts for selective oxidation of BA with and without water.

\begin{tabular}{|c|c|c|c|c|c|}
\hline Entry & Catalyst & Solvent & Tim. (h) & $\begin{array}{l}\text { Conv. } \\
(\%)\end{array}$ & $\begin{array}{l}\text { TOF. }{ }^{a}(h \\
\text { 1) }\end{array}$ \\
\hline 1 & $\mathrm{Pd} / \mathrm{MgAl}-\mathrm{LDO}$ & Water and toluene & 0.5 & 97.8 & 231 \\
\hline 2 & $\mathrm{Pd} / \mathrm{MgAl}-\mathrm{LDO}$ & Toluene & 0.5 & 12.2 & 29 \\
\hline 3 & $\mathrm{Pd} / \mathrm{nMgO}$ & Water and toluene & 1 & 83.5 & 137 \\
\hline 4 & $\mathrm{Pd} / \mathrm{nMgO}$ & Toluene & 1 & 5.8 & 6 \\
\hline 5 & $\mathrm{Pd} / \mathrm{nZnO}$ & Water and toluene & 1 & 40.2 & 71 \\
\hline 6 & $\mathrm{Pd} / \mathrm{nZnO}$ & Toluene & 1 & 6.58 & 8 \\
\hline 7 & $\mathrm{Pd} / \mathrm{SiO}_{2}$ & Water and toluene & 2 & 12.0 & 22 \\
\hline 8 & $\mathrm{Pd} / \mathrm{SiO}_{2}$ & Toluene & 2 & 4.9 & 8 \\
\hline 9 & $\mathrm{Pd} / \mathrm{ZrO}_{2}$ & Water and toluene & 3 & 30.5 & 27 \\
\hline 10 & $\mathrm{Pd} / \mathrm{ZrO}_{2}$ & Toluene & 3 & 9.2 & 10 \\
\hline 11 & $\mathrm{Pd} / \mathrm{nSiC}$ & Water and toluene & 2 & 33.8 & 34 \\
\hline 12 & $\mathrm{Pd} / \mathrm{nSiC}$ & Toluene & 2 & 9.4 & 8 \\
\hline 13 & $\mathrm{Pd} / \mathrm{AC}$ & Water and toluene & 4 & 33.5 & 17 \\
\hline 14 & $\mathrm{Pd} / \mathrm{AC}$ & Toluene & 4 & 20.3 & 10 \\
\hline 15 & $\mathrm{Pd} / \mathrm{CNT}$ & Water and toluene & 2 & 25.6 & 39 \\
\hline 16 & $\mathrm{Pd} / \mathrm{CNT}$ & Toluene & 2 & 18.7 & 18 \\
\hline
\end{tabular}

Reaction conditions: $\mathrm{BA}(2 \mathrm{mmol})$, catalysts $(45 \mathrm{mg}), 85^{\circ} \mathrm{C}$, toluene or $1: 1$ of toluene and water mixed

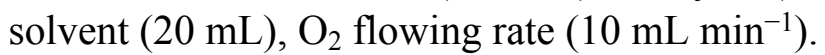

a: $\mathrm{TOF}=($ mole number of converted BA) $/($ total Pd atoms) $/($ reaction time, $\mathrm{h}), 4 \mathrm{wt} \% \mathrm{Pd}$ (experiment value). 
Table S5. Catalytic performance of $\mathrm{Pd} / \mathrm{MgAl}-\mathrm{LDO}$ for oxidation of various alcohol substrates in

\begin{tabular}{|c|c|c|c|c|c|}
\hline Entry & Substrate & Solvent & $\begin{array}{c}\text { Time. } \\
\text { (h) }\end{array}$ & $\begin{array}{c}\text { Conv. } \\
(\%)\end{array}$ & TOF. ${ }^{a}\left(h^{-1}\right)$ \\
\hline 1 & & Water and toluene & 0.5 & 97.8 & 231 \\
\hline 2 & & Toluene & 0.5 & 12.2 & 29 \\
\hline 3 & & Water and toluene & 0.5 & 97.7 & 231 \\
\hline 4 & & Toluene & 0.5 & 12.27 & 29 \\
\hline 5 & & Water and toluene & 2 & 96.4 & 138 \\
\hline 6 & & Toluene & 2 & 12.4 & 17 \\
\hline 7 & & Water and toluene & 5 & 20.5 & 8 \\
\hline 8 & & Toluene & 5 & 1.49 & 2 \\
\hline 9 & & Water and toluene & 5 & 15.7 & 8 \\
\hline 10 & & Toluene & 5 & 4.6 & 4 \\
\hline 11 & & Water and toluene & 5 & 14.4 & 7 \\
\hline 12 & & Toluene & 5 & 4.4 & 4 \\
\hline
\end{tabular}

toluene or toluene and water mixed solvent.

Reaction conditions: substrates $(2 \mathrm{mmol})$, catalysts $(45 \mathrm{mg}), 85^{\circ} \mathrm{C}$, toluene or $1: 1$ of toluene and water mixed solvent $(20 \mathrm{~mL}), \mathrm{O}_{2}$ flowing rate $\left(10 \mathrm{~mL} \mathrm{~min}^{-1}\right)$.

a: $\mathrm{TOF}=($ mole number of converted BA $) /($ total $\mathrm{Pd}$ atoms $) /($ reaction time, $\mathrm{h}), 4 \mathrm{wt} \% \mathrm{Pd}$ (theory value $).$

\section{REFERENCES}

1. Yu, J.; Yu, C.; Guo, W.; Wang, Z.; Li, S.; Chang, J.; Tan, X.; Ding, Y.; Zhang, M.; Yang, L.; Xie, Y.; Fu, R.; Qiu, J., Decoupling and correlating the ion transport by engineering 2D carbon nanosheets for enhanced charge storage. Nano Energy 2019, 64, 103921.

2. Kresse, G.; Furthmüller, J., Efficient iterative schemes for ab initio total-energy calculations using a plane-wave basis set. Phys. Rev. B. 1996, 54 (16), 11169-11186.

3. Perdew, J. P.; Burke, K.; Ernzerhof, M., Generalized Gradient Approximation Made Simple. Phys. Rev. Lett. 1996, 77 (18), 3865-3868.

4. Prystupa, D.; Anderson, A.; Torrie, B., Raman and infrared study of solid benzyl alcohol. J. Raman Spectrosc. 1994, $25,175-182$.

5. Kuiper, A. E. T.; Medema, J.; Van Bokhoven, J. J. G. M., Infrared and Raman spectra of benzaldehyde adsorbed on alumina. J. Catal. 1973, 29 (1), 40-48. 